\title{
System Approach and Simulation Modeling for Innovative Projects Efficiency
}

\author{
Ekaterina V. Orlova \\ Ufa State Aviation Technical University Ufa, Russian Federation \\ ekorl@mail.ru
}

\begin{abstract}
The problem of a comprehensive assessment of the effectiveness of enterprises' innovative activities is considered. The multidimensional criterion has been developed for a comprehensive assessment of innovative projects efficiency, providing a justification for the project quality and its quantitative assessment, taking into account the social, economic, and environmental components of its efficiency. A conceptual scheme of the approach to assessing innovation projects efficiency on the basis of the principle of nonlinear synthesis of indicators, which reflects the multistep process for its identification, has been proposed. The systemdynamic model for a comprehensive assessment of innovative project efficiency in the raw materials production for an antiarrhythmic drug is proposed. The model differs from the existing ones in that it takes into account the multiplicative influence of the factors that allows reproducing the system (synergetic) effect of the project.
\end{abstract}

Index Terms-system approach, simulational modeling, system efficiency, innovative project

\section{INTRODUCTION}

The categories "effectiveness" and "efficiency" are widely used in various fields of science and practice. Problem of evaluation of the enterprises' efficiency with the tasks of managing its functioning and development has been and remained one of the key topics in economy and management. This problem is highlighted in modern research since innovative path of economic development and the need to increase the changes rates in current management mechanism. The phenomenon of efficiency is studied by various economic schools, scientists in the field of control theory, system analysis and modeling. But still an approach to evaluate, to predict and to manage the economic efficiency of the enterprise as a complex dynamic multi-level organizational system, taking into account interrelated, often stochastically, parameters and particular indicators of subsystem has not yet been developed.

\section{ENTERPRISES' EFFICIENCY: ANALYSIS OF EXISTING METHODS}

Efficiency is one of the system quality characteristics, the ability to produce a certain effect. The efficiency of the system is determined by the ratio of costs and results of the system proccesing. Depending on what costs and what results are taken into account, they distinguish between the types of effects and efficiencies - organizational, productional, commercial, social, environment and budget effects.

Economic efficiency reflects the system ability to produce an economic effect in its processing. The greater economic effect (result) and the less the resources cost to obtain this result, the higher the economic efficiency. In some cases, the economic efficiency assessment is limited by the ratio between the results and the costs. Such definition is historically formed in the neoclassical economic school (J. M. Keynes, A. Pigou, H. Leibenstein; And Ansoff, P. Drucker, G. Mintzberg) [1][4].

Principles of marginal economic efficiency are formulated by V. Pareto belong the central concepts in modern economic science. According to these principles economy and production are effective if the state and society derives maximum utility from existing resources and it is impossible to improve the values of some system characteristics without affecting others. This definition is used in the theory of welfare, which studies the processes of equitable resources distribution in the economy and its effectiveness.

In system approach an enterprise is usually presented as a black box, while the internal system structure is not disclosed, and only the entrance to the model (resources) and exit from it (effects) are studied (J. Neumann, O. Margenshtern, J. Tinbergen, C. Cobb, P. Douglas, R. Solow, K. Arrow, L.V. Kantorovich, V.N. Livshits, R.M. Nizhegorodtsev, I.V. Gontareva) [5]-[11].

Identification of a system efficiency as a resource intensity of the result has a number of obvious drawbacks [11]. Resource intensity does not reflect the timeliness, necessity and sufficiency of beneficial effect. The same efficiency level is achieved with various combinations of the numerator and denominator and not taking into account their absolute values. In addition, the efficiency sources are not clear, therefore, it is not clear how to manage it. Profit is more determined by the market situation than the costs incurred.

Finally, it does not specify what effects and costs should be included in the overall assessment of the system quality, what synergetic effects arise when the various subsystems interact with each other. Therefore, in evaluating the effectiveness it is necessary to reveal the complex structure of causal relationships between the result and the factors that determined it in the form of costs, resource potential, development ability, etc.

In the system analysis and management efficiency is the complex operational property characterizing the system's processing quality and the degree of its adaptability to achieving the goal (B.S. Fleishman, D. Nort, D. Norton, R. Kaplan, D.S. Lvov, G.B. Kleiner, V.N. Volkova, V.E. Dementiev, V.S. Anfilatov, D.A. Novikov, G.A. Ugolnitsky, 
(functional, operational) properties (efficiency, resource intensity, efficiency, productivity, accuracy, profitability).

The first two properties groups determine the quality of the system as a condition of its suitability for the intended use. The third properties group determines the operational efficiency, that is, the efficiency of the system's functioning process, which characterizes its adaptability to achieve the system goal. Then the system efficiency of the enterprise (project, program) can be represented as a comprehensive (systemic) assessment of the quality of its structure and the quality of its functioning. Efficiency can be characterized by a number of heterogeneous components and indicators of both quantitative and qualitative nature. Organization of system efficiency is reduced to the procedure for identifying the essential components, the determination of the conditions for the occurrence and the justification of the factors determining this effect.

We suggest an economic process of the economic system (enterprise) of two types of operations (processes). The first operations determine the main processes of the enterprise functioning - production, distribution, exchange and consumption, which require a combination of resources for their implementation. The second type of operation is management processes - planning, organization, accounting, control and coordination.

The efficiency of the business process of enterprise can be identified with two groups of characteristics [23]-[25]:

- an allocative efficiency is indicates productivity of resources distribution and its economical spending;

- an adaptive efficiency is characterizes effectiveness of goals and objectives fulfilling the and the degree of adaptability of various subsystems to be changed.

By specialization of business processes allocative efficiency combines the efficiency of production, distribution, exchange and consumption processes; adaptive - the efficiency of the processes of planning, organization, accounting, control and coordination. By types and areas of dissemination of enterprise results we distinguish commercial (economic), budgetary, social, environmental types of effects and efficiencies. It is important that the operational efficiency of the enterprise as a whole is determined by a set of partial indicators reflecting allocative and adaptive efficiency, as well as their aggregation according to certain rules. Therefore, studies aimed to assessing the interaction and identifying the relationship between different types of efficiencies, as well as their contribution to the overall system efficiency of the system, seem very promising.

Allocative efficiency determines how productively these or other resources are distributed, and also how economically they are spent. The efficient resources allocation reflects the optimal level of combination of products with the most efficient resources combination. At the same time, an optimal combination of resources means such a production that is purchased by consumers in a competitive market at a price based on real production costs, and an effective combination of resources means the production of these products with oroperties (connectivity, organization, complexity, scale, centralization) and behavioral

We distinguish a number of essential properties from an enterprise as a system. These properties can be conditionally divided into three groups: system-wide properties (integrity,
stability, controllability, observability, determinism, openness,

of the agent's activity, as results achievable within a certain the entire enterprise - supersystem circuit is stable. A similar situation arises when the products demand of an enterprise enterprise is effective if it is harmonized in terms of supply The analysis of existing approaches in the field of identification and evaluation of system efficiency of enterprises approach for efficiency assessment. The system efficiency considering all types of business activities (production, impact of these activities on the environment - nature and society.

\section{SyStem APPROACH FOR PRODUCTION AND ECONOMIC EFFICIENCY EVALUATION}




\section{THE CONCEPT For AsSESSMENT OF INNOVATIVE PROJECTS SYSTEM EFFICIENCY}

Traditionally, innovative projects in enterprise are described only from from one point: from the point of their commercial (economic) effectiveness using indicators such as net present value, payback period and profitability index, or from the point of their social significance or from the point of their environmental efficiency. However, there is no formalized approach for the simultaneous assessment of different types of project impacts and different types of its efficiency. For a number of projects that significantly affect the environment and society, such an assessment seems to be the most adequate and appropriate to the project essence.

For example, there are projects that have a significant impact on the ecological state of the environment (pollution of water, air and soil resources), as well as projects that have only a social orientation and have only social efficiency (improve the quality of life). Other projects have strongly marked economic, social and environmental effects, such as projects to create new types of technologies for the production of medicines. Therefore, a comprehensive multidimensional criterion is needed to assess the effectiveness of innovative projects, which would provide a justification for the project quality and its quantitative assessment, taking into account the environmental, social and economic components of its efficiency.

We note that only the operational component of system efficiency, which reflects the project process, is further evaluated. The component of system efficiency associated with the structural component is not considered.

The formalized criterion for assessing the system (integrated) efficiency of an innovative project is: $S E=f(E E, C E, E c E)$, where $S E$ is systemic efficiency, $E E$ is economic efficiency, $C E$ is social efficiency, $E c E$ is environmental efficiency. The conceptual approach to the step by step assessment of the system efficiency of a project, reflecting an assessment of social, economic and environmental efficiencies, as well as the tools and results for the analysis of individual types of efficiency in a single criterion, is shown in Fig. 2. The type of innovation may be different - a new product or a new technology for the production of a well-known product.

We assess the system efficiency of an innovative project in three steps. At the first step we select homogeneous products for the production of which an innovative technology is being developed, from the perspective of social efficiency. In order to rank products according to the degree of their usefulness from the point of the selected criteria, a hierarchy analysis method is used. The hierarchy analysis method includes procedures for synthesizing multiple judgments, identifying priority criteria and for finding alternative solutions. The result of this analysis is the vector of various products priorities, ranked in decreasing social efficiency of the product. An example of such product is the drugs production aimed at treating a specific type of disease. Various drugs are subject to study, having one or another effectiveness, taking into account the criteria of their usefulness and detriment to humans. The
The technology for efficiency management of the enterprise as a whole should take into account the activity of economic agents, which can manifest it in distorting information, choosing decisions that do not coincide with the plan, dishonest behavior [28]-[30]. 


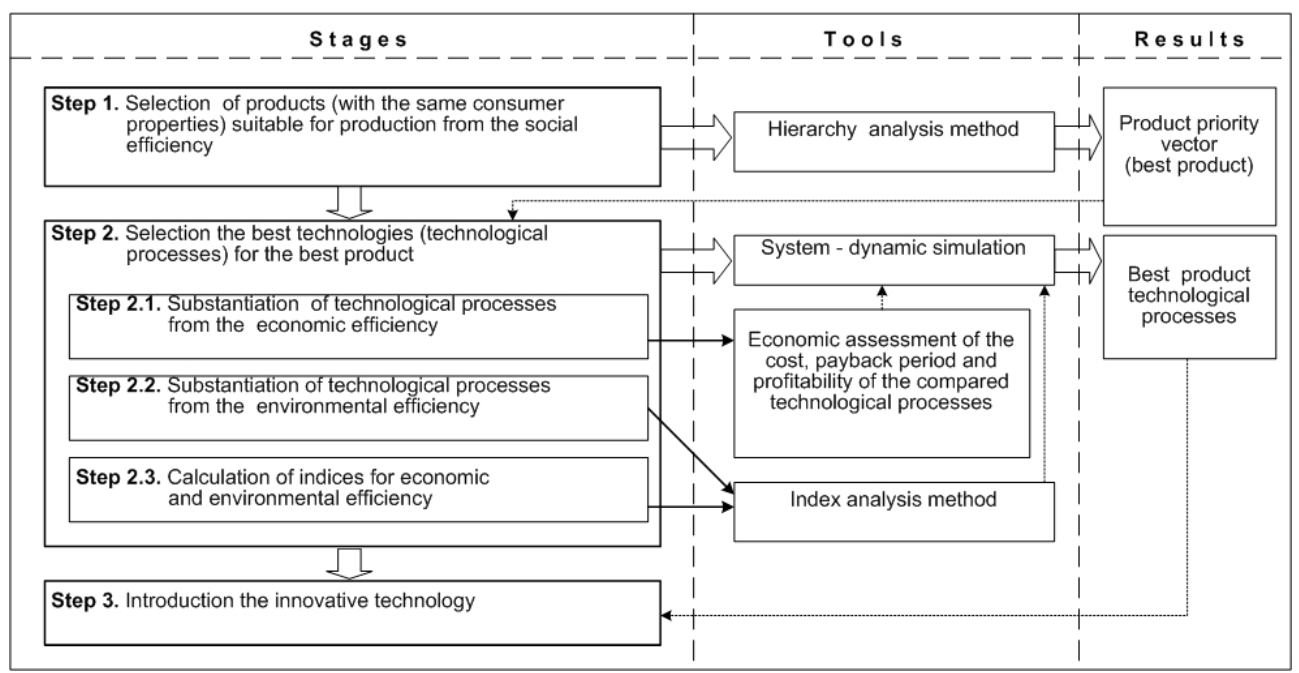

Fig. 2. The conceptual scheme of the approach for system efficiency evaluation of innovative projects.

highest weight in the priority vector has the drug, which has the maximum social effect.

At the second step we select and justify the most promising production technology for this product and consist of three sub-stages. First, we assess the economic efficiency of production technology and we use three indicators net present value, payback period and profitability index. As an example, various production technologies, selected as the best drug in the first stage, can be cited. At the next step we evaluate the environmental efficiency of the selected production technology of the best drug, taking into account environmental pollution indicators. At the third step of this stage we calculate the indices for the economic and environmental performance. To calculate the economic efficiency indices we compare the net present value, payback period and profitability index for the compared production technologies. We compare the technology for active substances synthesis for the medicinal product in laboratory conditions and the technology for substances synthesis based on bioraw materials obtained by the method of collection in natural conditions. If the indices exceed one, then the compared technology (whose indicator is in the numerator) is more costeffective.

Environmental efficiency is an assessment of the impact of the product manufacturing process on the environment and its degree of pollution. The determinants of environmental efficiency are indicators of soil, air, and water pollution. These are indicators of desertification and deterioration of soil quality, decrease in productivity, etc. Synthesis of the environmental efficiency index is carried out on the basis of pairwise comparison of the relevant indicators for the compared technologies. The priority production technology should have the characteristics of the degree of contamination in terms of values lower compared to competing (less environmentally friendly) technology.

At the third step, the process of introducing the best production technology of the best product into production is implemented. The stage affects the organizational and economic mechanisms for the implementation of the production process.

\section{The Simulation Model for Innovative Project SYSTEM EFFICIENCY}

To model the system efficiency of an innovative project implementation under uncertainty of different factors and their complex relationships we use the system-dynamic modeling approach and Anylogic simulation software. The advantage of the simulation method in solving this problem is that it is possible to sufficiently deeply analyze the complex causal relationships of factors of economic, environmental and social efficiency, to investigate the stochastic processes, to conduct many experiments with various values of input variables and parameters.

We examine the innovative project "Biotechnological production of raw materials for a medicinal product". The aim of this project is the high-tech production of a drug for the treatment of arrhythmia. The novelty of the project is the synthesis in laboratory conditions of the roots of aconite and the extraction of the substance lappaconitine from them as the main active substance that is part of the drugs for the treatment of arrhythmia. The difference of this technology is in the rejection from the collection of aconite roots in natural conditions, which contributes to the conservation of plant biomass.

The effectiveness of this project depends on many different factors that are subject to change over time. In order to make it possible to conduct a series of experiments to influence these changes on the individual components of system efficiency we design the system-dynamic model. The resulting indicators of modeling are net present value (NPV), payback period, profitability index and an indicator characterizing environmental efficiency - the environmental efficiency index.

Under simulation experiments we conduct and assess the influence of the following factors on the project performance indicators and on their sensitivity to changes in these factors: 
TABLE I

THE RESULTS OF SIMULATION EXPERIMENTS

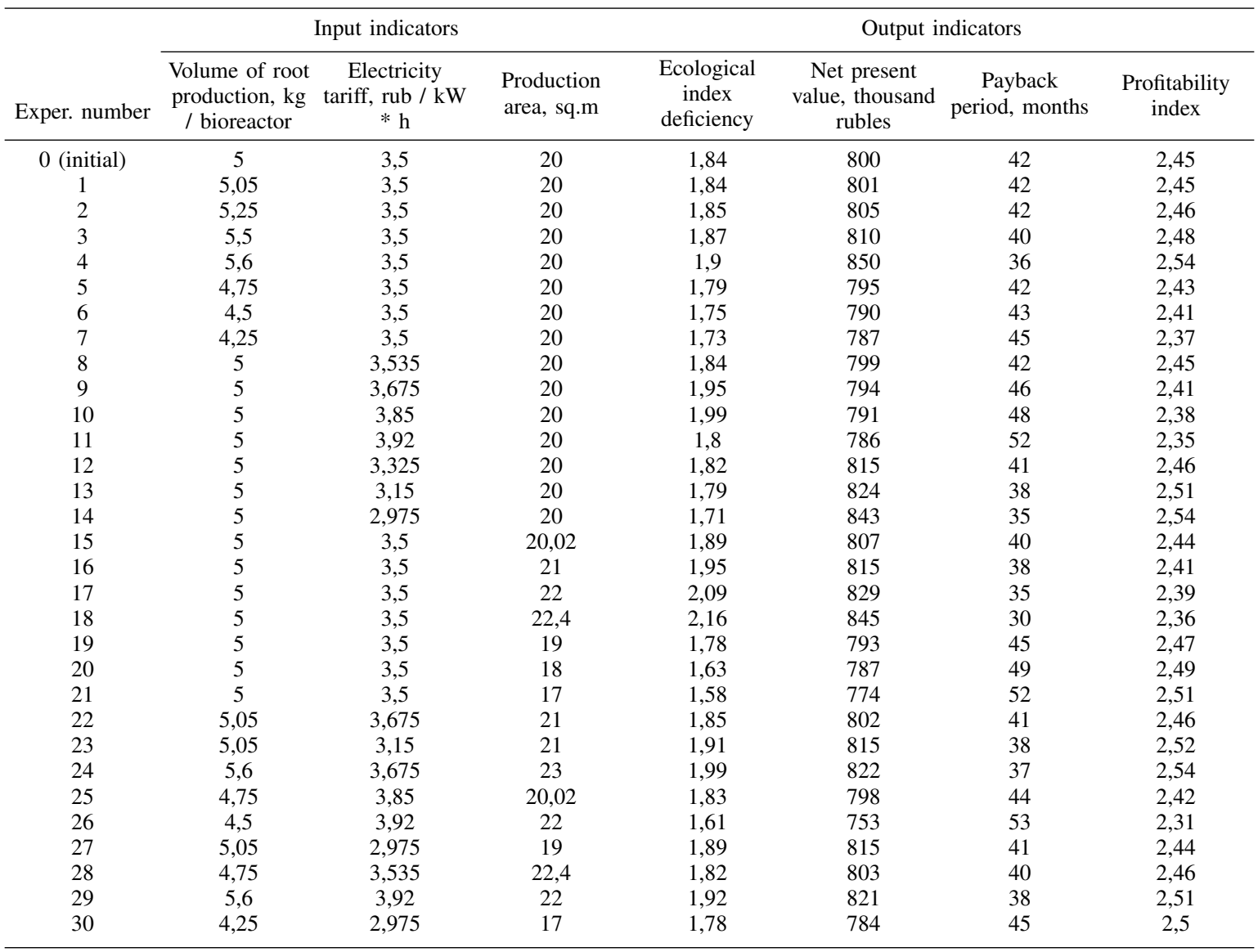

the volume of root production, the electricity tariff and the floor space required for the placement of laboratory equipment.

The selected factors are justified by the following circumstances. Firstly, the "electricity tariff" and the total electricity costs are important, since in the structure of the production cost (aconite roots) it is about 50\%. Secondly, the factor "production area" and "production volume" are important from the point of view of a significant impact on the consumption of products obtained from aconite roots. Thus, the volume of demand is 12,000 tons of aconite roots per year, over an area of 20 square meters and can accommodate about 8 bioreactors, providing the production of $600 \mathrm{~kg}$ of roots per year. These amounts provide about 4 million packages of the drug. The need for a drug of this class is 90 million packs per year in Russia.

We carry out the series of simulation experiments. We study the changing of each factor individually, and their joint changing and their affects on the resulting project performance indicators. The results of simulation experiments in various combinations in factors and their combined change are presented in Table I.

An analysis of the simulation experiments results are showed that the consequences of scenario 4, that is, with an increase in root production by $12 \%$ per year, there is an increase in the environmental efficiency index, profitability index and net present value, but the payback period of the project is reduced. The consequences of scenario 11, that is, with an increase in the electricity tariff by $12 \%$, there is a decrease in the environmental efficiency index and an increase in the payback period, a decrease in the net present value of the project and the project profitability index. Scenario 18, in contrast, with $12 \%$ increase in production space provides an growth in the environmental efficiency index and the net present value and reduces the payback period of the project. The simultaneous use of two mechanisms (scenario 24) - an increase in the volume of root production by $10 \%$ and an increase in production area by $15 \%$ provides a larger growth in the environmental efficiency index, net present value and profitability index while reducing the payback period even with a $5 \%$ increase in electricity tariffs.

Thus, the phased implementation of the proposed approach to a comprehensive assessment of the innovative project "Biotechnological production of raw materials for a drug" efficiency showed the following. In comparing with a competing technology of the production of a medicinal antiarrhythmic drug from aconite roots obtained in natural conditions, the technology of its laboratory synthesis has several proven advantages. Firstly, to provide about 4 million packages of a drug for the Russian market it is required to produce about $600 \mathrm{~kg}$ of aconite roots per year. The environmental friendliness of the new technology is two 
[4] M. Alle, Conditions of efficiency in the economy. Moscow: SIC "Science for society", 1998

times higher than the environmental friendliness of the old production technology, which is its undoubted advantage. Secondly, such volume of the drug will ensure the maximum social effectiveness of the project, consisting in the growth of public health and life quality. Thirdly, a higher level of technology efficiency has been proved: labor costs for this project are five times lower than for a competing one, production costs are two times lower. The estimated values of the indicators of economic efficiency of the project at a high level - net present value is more than 800 thousand rubles, the payback period is 42 months and the project profitability index is 2.45 .

\section{CONCLUSION}

In this work we have established that traditional approaches and methods for system assessment of the enterprise (project) efficiency do not provide simultaneous accounting of indicators of social, economic and environment efficiencies. We have proved that these methods do not provide projects identification from the point of social orientation, competitiveness and environmental friendliness.

We have developed the comprehensive multidimensional criterion for assessing the system efficiency of projects. It provides the projects quality justification and its quantitative assessment, taking into account the social, economic and environmental components of its effectiveness. We have proposed the conceptual scheme of the approach for system efficiency evaluation of innovative projects. This approach is based on the principle of nonlinear synthesis of system efficiency indicators, which reflects the process for its identification. This concept has not previously been presented in existing methods for innovative projects efficiency evaluation.

We have designed the system-dynamic model for a comprehensive assessment of the innovative project efficiency for the production of raw materials for an antiarrhythmic drug. This model provides situational analysis and modeling of the impact of changes in project on the efficiency factors. The model differs from the existing ones in that it takes into account the multiplicative factor effects that allow to reproduce the system (synergetic) effect of the project implementation.

Experimental studies of the proposed approach on the actual data on the implementation of a specific project were carried out and the reliability of the proposed theoretical principles and the developed method of a comprehensive assessment of the innovative project efficiency were proved. The testing results of the proposed theoretical principles and approach have a great practical significance.

\section{REFERENCES}

[1] A. C. Pigou, The economics of welfare. London: Macmillan, 1920.

[2] H. Leibenstein, "Allocative efficiency vs. X-efficiency," The American Economic Review, vol. 56, no. 3, pp. 392-415, 1966.

[3] P. Drucker, Effective management. Moscow: Publishing and trading house "Grand", 2003.
[5] K. J. Arrow, "The potentials and limits of the market in resource allocation," in Issues in Contemporary Microeconomics and Welfare, G. Feiwel, Ed., 1985.

[6] D. C. North, "Economic performance through time," Lecture to the memory of Alfred Nobel, 1993.

[7] D. North, "Institutions, institutional changes and the functioning of the economy," Moscow: Fund of the economic book "Beginnings", p. 180, 1997.

[8] D. Neumann and O. Morgenstern, "Game theory and economic behavior," Moscow: Science, p. 780, 1970.

[9] L. Kantorovich, "Mathematical and economic work," Novosibirsk: Science, p. 760, 2011.

[10] M. Blaug, "Economic thought in retrospect," The Case of Ltd, pp. 714$720,1994$.

[11] I. Gontareva and R. Nizhegorodtsev, "Systemic effectiveness of an enterprise: essence, factors, structure," Moscow-Kirov: Russian Higher Economic Research Institute, p. 182, 2012.

[12] V. Livshits, "Fundamentals of systems thinking and systems analysis," Moscow: Institute of Economics RAS, p. 54, 2013

[13] V. Anfilatov, A. Emelyanov, and A. Kukushkin, "System analysis in management," Moscow: Finance and Statistics, p. 358, 2008.

[14] G. B. Kleiner, Strategy of the enterprise. Moscow: Publishing House Delo ANH, 2008.

[15] G. Kleiner et al., "System economics as a platform for development of modern economic theory," Ekonomics, vol. 6, pp. 4-28, 2013.

[16] B. Fleishman, "The theory of the potential effectiveness of complex systems," Moscow: Publishing house "Soviet Radio", p. 224, 1971.

[17] O. Sukharev, "Theory of economic efficiency," Finance and statistics, vol. 6 , p. 368, 2009

[18] — "Economic growth, institutions and technology," Moscow: Finance and Statistics, p. 446, 2014.

[19] — The theory of dysfunction of economic systems and institutions. Moscow: Lenard, 2014.

[20] V. Volkova and A. Denisov, "Theory of systems," Moscow: Higher school, p. 551, 2006.

[21] D. Novikov, Theory of Management of Organizational Systems. Moscow: Fizmatlit, 2012

[22] G. Ugolnitsky, "Management of sustainable development of active systems," Rostov-na-Donu: Publisher SFU, p. 940, 2016.

[23] E. Orlova, "Approach for the coordinated control in production and economic system," in Proceedings of the 30th International Business Information Management Association Conference (IBIMA). Vision 2020: Sustainable Economic development, Innovation Management, and Global Growth, Madrid, 2017, pp. 704-712.

[24] , "Technology for control an efficiency in production and economic system," in Proceedings of the 30th International Business Information Management Association Conference (IBIMA). Vision 2020: Sustainable Economic development, Innovation Management, and Global Growth, Madrid, 2017, pp. 811-818.

[25] — "Modeling and coordinated control for the production and economic system," in Proceedings of the Mathematical Modeling Session at the International Conference Information Technology and Nanotechnology (MM-ITNT 2017). Samara, Russia, vol. 1904, 2017, pp. 1-6.

[26] —, "Modeling and coordinated control for the production and economic system," in Proceedings of the 30th International Business Information Management Association Conference (IBIMA). Vision 2020: Sustainable Economic development, Innovation Management, and Global Growth, Madrid, 2017, pp. 827-837.

[27] E. V. Orlova, "Economic efficiency of the mechanism for credit risk management," in Proceedings of the Workshop on Computer Modelling in Decision Making (CMDM 2017). Aachen, CEUR-WS, vol. 2018, 2017, pp. $139-150$.

[28] E. Orlova, "An approach for modeling and situational management of industrial product efficiency," IEEE, in press.

[29] — "Mechanism, models and control algorithms for productive and economic system under harmonization criteria of interested agents," Software Engineering, no. 2, pp. 86-96, 2016.

[30] E. V. Orlova, "Model for operational optimal control of financial recourses distribution in a company," Computer Research and Modeling, vol. 11, no. 2, pp. 343-358, 2019. 